\title{
Eradication of neoplastic Barrett's esophagus in patients with esophageal varices with a modified endoscopic mucosal resection technique and radiofrequency ablation
}

Most patients with cirrhosis and portal hypertension eventually require liver transplantation. Esophageal neoplasia in this population (especially in patients who use alcohol and tobacco) might contraindicate liver transplantation. Early Barrett's neoplasia should be treated with endoscopic resection if there are no signs of advanced adenocarcinoma, and com- plete eradication of all remaining Barrett's epithelium should be striven for, preferably with radiofrequency ablation (RFA) [1]. However, these treatments may become challenging in patients with portal hypertension and esophageal varices, due to the risk of variceal bleeding and hepatic decompensation. Some reports have been published of endoscopic resection after a session of endoscopic variceal ligation, but without RFA for eradication therapy $[2,3]$. We present a case series of three patients with esophageal varices and Barrett's neoplasia successfully treated with a modified endoscopic resection technique and RFA ( $\triangleright$ Table 1 ).

- Table 1 Clinical characteristics and outcomes of three patients with Barrett's esophagus and esophageal varices treated with a modified endoscopic mucosal resection technique and radiofrequency ablation.

\begin{tabular}{|c|c|c|c|}
\hline & Case $1^{*}$ & Case 2 & Case 3 \\
\hline Age (years)/gender & $51 /$ male & $52 /$ male & $63 /$ male \\
\hline Prague classification & C6M7 & C7M12 & $\mathrm{C} 2.5 \mathrm{M} 5$ \\
\hline Prior histology (biopsies) & HGD & HGD & HGD \\
\hline Worst final histology & HGD & pT1a (intramucosal) & pT1a (intramucosal) \\
\hline Number of lesions & Multifocal (>3) & 1 & 1 \\
\hline No. of sessions of EMR & 5 & 3 (due to LGD in lateral margins) & 1 \\
\hline No. of sessions of RFA & 2 & 3 & 3 \\
\hline Complete eradication of dysplasia & Yes & Yes & Yes \\
\hline Complete eradication of intestinal metaplasia & Unknown & Yes & Yes \\
\hline Follow-up after complete eradication of dysplasia (months) & 13 & 24 & 36 \\
\hline $\begin{array}{l}\text { Follow-up after complete eradication of intestinal metaplasia } \\
\text { (months) }\end{array}$ & - & 14 & 29 \\
\hline Etiology of cirrhosis & $\mathrm{HCV}$ and alcohol & Alcohol & Alcohol \\
\hline Child-Pugh/MELD score & A-6/9 & B-8/15 & A-6/11 \\
\hline Platelet count, $10^{3} / \mu \mathrm{L}$ & 145 & 80 & 141 \\
\hline INR & 1.14 & 1.54 & 1.37 \\
\hline Size of varices & Large & Large & Large \\
\hline Previous esophageal bleeding & Yes & No & No \\
\hline NSBB prophylaxis (baseline) & Yes & No & Yes \\
\hline Hiatal hernia size $(\mathrm{cm})$ & 3 & 5 & 3 \\
\hline Post-EMR bleeding & No & Yes (scar bleeding) & No \\
\hline Other complications & No & No & No \\
\hline
\end{tabular}




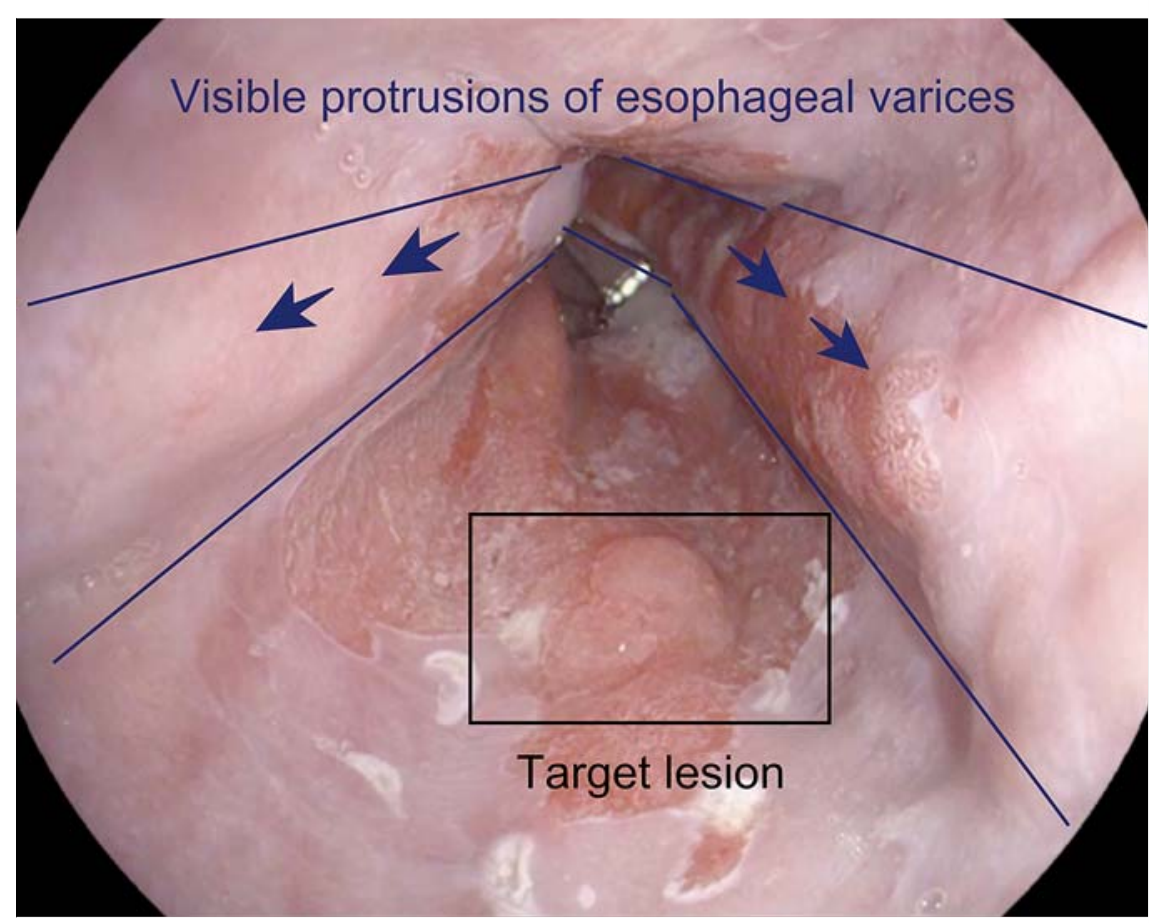

- Fig. 1 The flow of the esophageal varices is from distal to proximal in the esophagus, as shown by the arrows. The target lesion is adjacent to the esophageal varices.

Esophageal varices were confirmed by endoscopic ultrasound on prior endoscopy. All procedures were performed with the patient under deep sedation, and with antibiotic prophylaxis and somatostatin perfusion. After identifying and marking the target lesion, we "blocked" the distal-to-proximal variceal flow by endoscopic band ligation of visible esophageal varices distal to the lesion. Conventional band ligation-assisted endoscopic mucosal resection (EMR) of the target lesion was then performed in the same session ( $>$ Fig. 1, $>$ Fig. 2). Another EMR session was used if needed. When the lesions were completely removed, RFA was performed in a further session until complete eradication of Barrett's esophagus was achieved ( Video 1, Case 3). No intraprocedural complications occurred. One patient presented delayed bleeding 8 days after EMR, but this did not require endoscopic treatment. No other relevant complications were seen.
In conclusion, EMR of dysplastic lesions in Barrett's esophagus with underlying esophageal varices, followed by RFA for complete eradication, is feasible. The use of band ligation to decrease the blood flow prior to EMR may be helpful.

Endoscopy_UCTN_Code_TTT_1AO_2AF

Competing interests

The authors declare that they have no conflict of interest.

The authors

Hugo Uchima ${ }^{1,2,3}$, Michel Blé3, David Busquets ${ }^{1}$, Isabel Serra ${ }^{1}$, Carmen López ${ }^{1}$, Xavier Aldeguer ${ }^{1}$, Carlos Huertas ${ }^{1}$

1 University Hospital Dr. Josep Trueta, Girona, Spain

2 Germans Trias i Pujol Hospital, Badalona, Spain

3 Endoscopy Unit, Teknon Medical Center, Quirónsalud Hospital, Barcelona, Spain

\section{Corresponding author}

\section{Hugo Uchima, MD}

Endoscopy Unit, Teknon Medical Center, Vilana 12 Planta 1, Barcelona 08017, Spain huchima.germanstrias@gencat.cat

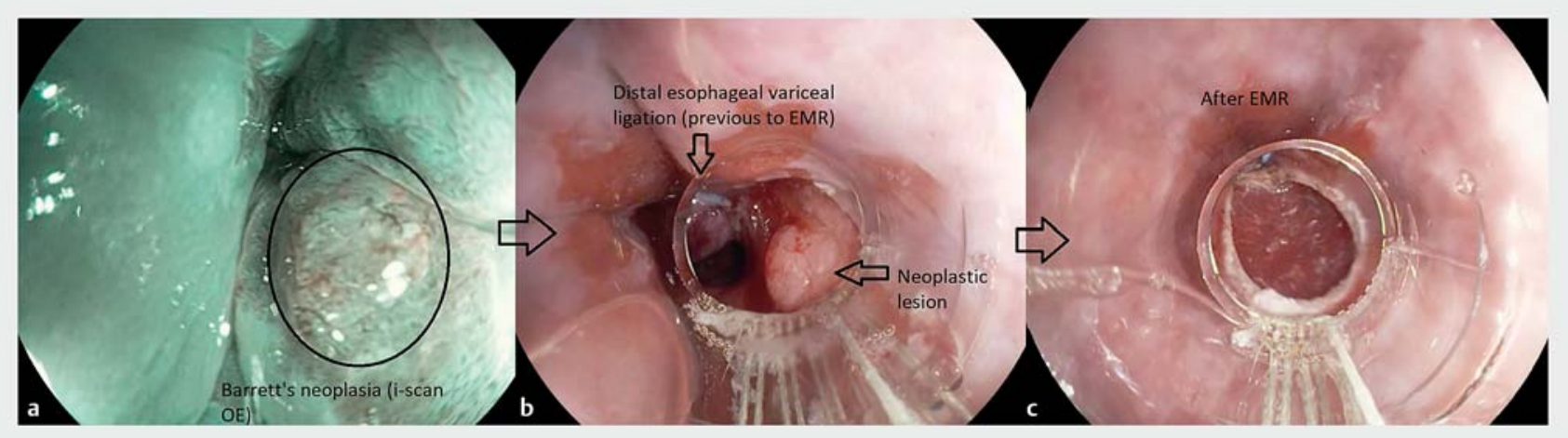

- Fig. 2 a-c Sequence of the modified band-ligation-assisted endoscopic mucosal resection (EMR). a The target lesion. b The esophageal varices are ligated distal to the target lesion to "block" the blood flow prior to EMR. c Post-EMR defect. 


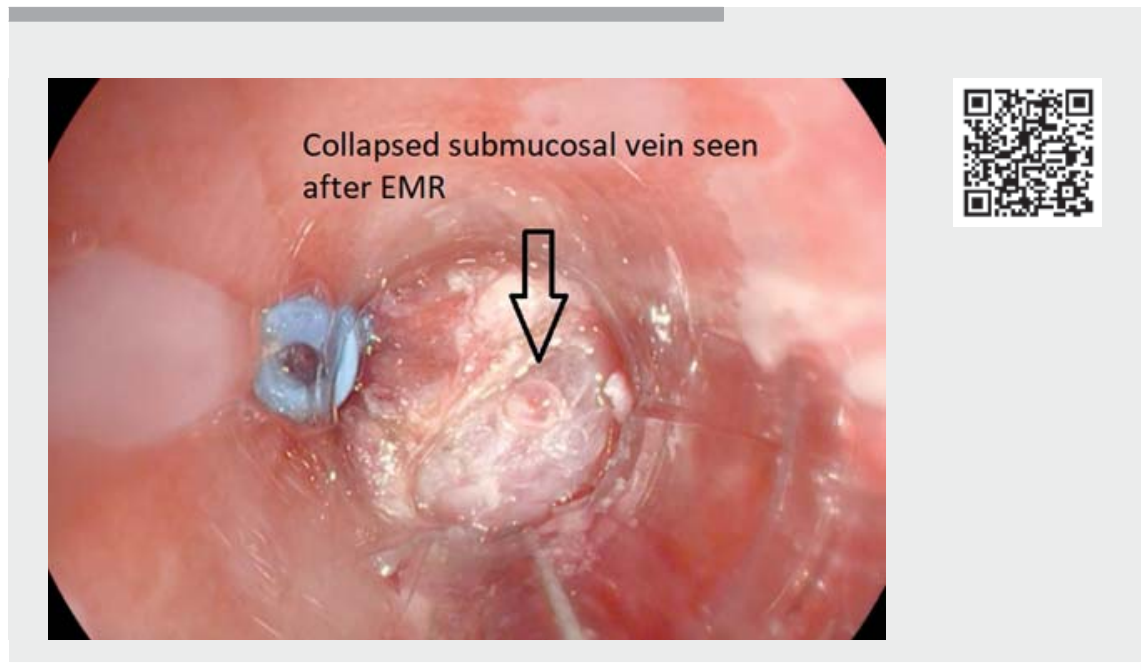

$\checkmark$ Video 1 Modified technique for endoscopic mucosal resection followed by radiofrequency ablation for eradication of neoplastic Barrett's esophagus in the presence of esophageal varices.

\section{References}

[1] Weusten B, Bisschops R, Coron E et al. Endoscopic management of Barrett's esophagus: European Society of Gastrointestinal Endoscopy (ESGE) Position Statement. Endoscopy 2017; 49: 191-198

[2] Prasad GA, Wang KK, Joyce AM et al. Endoscopic therapy in patients with Barrett's
Bibliography

Endoscopy 2022; 54: E261-E263

DOI $10.1055 / \mathrm{a}-1516-3400$

ISSN 0013-726X

published online 18.6.2021

(C) 2021. Thieme. All rights reserved.

Georg Thieme Verlag KG, Rüdigerstraße 14 , 70469 Stuttgart, Germany

\section{ENDOSCOPY E-VIDEOS}

https:|/eref.thieme.de/e-videos

口近 Endoscopy E-Videos is an 整到 回舴: reporting on interesting cases and new techniques in gastroenterological endoscopy. All papers include a high quality video and all contributions are freely accessible online. Processing charges apply (currently EUR 375), discounts and wavers acc. to HINARI are available.

This section has its own submission website at

https://mc.manuscriptcentral.com/e-videos 